\title{
Cardio-Pulmonary-Renal Consequences of Severe COVID-19
}

\author{
Goksel Guven $^{a, b}, c$ Can Ince ${ }^{a}$ Arzu Topelic Kadir Caliskan ${ }^{d}$

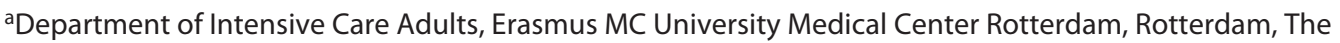

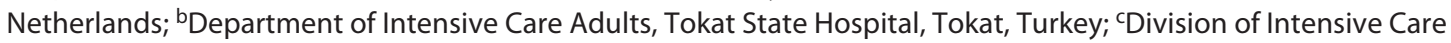 \\ Medicine, Department of Internal Medicine, Hacettepe University Faculty of Medicine, Ankara, Turkey; ${ }^{\text {Department }}$ \\ of Cardiology, Unit Heart Failure, Heart Transplantation \& Mechanical Circulatory Support, Thorax Center, \\ Rotterdam, The Netherlands
}

\section{Keywords}

Coronavirus disease 2019 . Cardiorenal syndrome · Acute kidney injury · Pandemic · Heart-lung interaction

\begin{abstract}
Severe acute respiratory syndrome coronavirus 2 has rapidly spread worldwide and resulted in the coronavirus disease 2019 (COVID-19) pandemic. The disease raised an unprecedented demand for intensive care support due to severe pulmonary dysfunction and multiorgan failure. Although the pulmonary system is the potential target of the COVID-19, recent reports have demonstrated that COVID-19 profoundly influences the cardiovascular system and the kidneys. Research studies on cadavers have shown that direct heart and kidney injury can be frequently seen in patients deceased due to COVID-19 infection. On the other hand, functional or structural dysfunction of the heart may deteriorate the renal function and vice versa. This concept is already known as the cardiorenal syndrome and may play a role in COVID-19. Proactive monitoring of micro- and macrohemodynamics could allow prompt correction of circulatory dysfunction and can be of pivotal importance in the prevention of acute kidney injury. Moreover, type and amount of fluid therapy and va-
\end{abstract}

karger@karger.com www.karger.com/crm

Karger $\stackrel{\text { ' }}{5}$
(C) 2021 The Author(s)

Published by S. Karger AG, Basel

This is an Open Access article licensed under the Creative Common Attribution-NonCommercial-4.0 International License (CC BY-NC) (http://www.karger.com/Services/OpenAccessLicense), applicable to the online version of the article only. Usage and distribution for commercial purposes requires written permission. soactive drug support could help manage these patients either with or without mechanical ventilator support. This brief review outlines the current evidence regarding the COVID-19-related renal and cardiorenal complications and discusses potential hemodynamic management strategies.

(c) 2021 The Author(s).

Published by S. Karger AG, Basel

\section{Introduction}

Coronaviruses (CoVs) are enveloped, positive singlestranded RNA viruses that lead to respiratory, cardiac, or intestinal infections in animals and humans. They consist of 4 subgroups: $\alpha-, \beta-, \delta$-, and $\gamma$-CoVs. Humans could be infected by various $\alpha-\mathrm{CoV}$ and $\beta-\mathrm{CoV}$, although $\delta-\mathrm{CoV}$ and $\gamma$-CoV mainly infect birds [1]. The critical importance of these viruses is their potential to cause pandemics. In the last 2 decades, 3 overwhelming outbreaks of viral pneumonia caused by CoVs were reported to spread around the world. First in 2002, severe acute respiratory syndrome virus originated in China and caused around 800 deaths worldwide, with an $11 \%$ mortality rate [2]. A decade later in 2012, Middle East respiratory syndrome virus was first reported in Saudi Arabia and affected 2,494 
people with a fatality rate of $34 \%$ [3] [1-55]. And again, almost a decade later, severe acute respiratory syndrome coronavirus 2 (SARS-CoV-2) appeared in late 2019 again in China and was called coronavirus disease 2019 (COVID-19). Since then, COVID-19 has rapidly spread worldwide, leading to classification as a pandemic by the World Health Organization on March 11, 2020 [4].

When COVID-19 was first presented itself, the SARSCoV-2 was thought to affect the upper and lower respiratory tract only. However, recent evidence suggests that COVID-19 is a multisystem inflammatory vasculopathy and centered around endothelial dysfunction $[5,6]$. Similar to severe acute respiratory syndrome virus and Middle East respiratory syndrome virus did, SARS-CoV-2 directly and indirectly causes cardiovascular and renal complications [7-9]. The concomitant development of acute myocardial or kidney injury is associated with significantly worse outcomes $[9,10]$. Underlying comorbidities such as hypertension, diabetes, obesity (i.e., metabolic syndrome), smoking, and cardiovascular diseases have been associated with increased risks for the development of severe complications of COVID-19 [11]. This is probably one of the reasons why the mortality and morbidity of COVID-19 infection is more prominent in the elderly population who have higher rates of these comorbidities [12].

The SARS-CoV-2 tightly binds to the host ACE- 2 receptor by its $S$ protein (S1). After that, cellular transmembrane serine proteases (TMPRSS) cleave the S1 protein so that the virus releases peptides to accomplish fusion to the host membrane [13]. Binding the ACE-2 receptor and TMPRSS is crucial for the virus to enter the cells, and this process occurs at the tissues which coexpress the ACE-2 receptor and TMPRSS $[13,14]$. The heart, lungs, kidney, and intestines are abundant in the ACE-2 receptor and TMPRSS. Depending on the type of the affected tissue and the severity of the inflammation, the clinical manifestation varies by dyspnea, cough, fever, myalgias, respiratory failure, diarrhea, proteinuria, myocarditis, arrhythmia, and neurologic symptoms [15]. In this report, we briefly review the pathogenesis of COVID-19 and its direct and indirect effects and mutual interactions of the heart, lungs, and kidneys.

\section{Cardiopulmonary Interaction and COVID-19}

In contrast to classic acute respiratory distress syndrome (ARDS), a hypothesis suggested that the COVID19-related ARDS has a unique pattern associated with ei- ther relatively low (type L) or normal/high (type $\mathrm{H}$ ) pulmonary elastance. L-type is characterized by high lung compliance and does not require high positive end-expiratory pressure (PEEP) and can tolerate high tidal volume without an increase in plateau and driving pressures. On the other hand, $\mathrm{H}$-type has a low lung compliance and shows a similar pattern to classic ARDS [16].

Determining the phenotypes of lung injury is clinically necessary to design the ventilator strategy and direct the hemodynamic management. Mechanical ventilation and applied settings (PEEP and tidal volume) influence highly the intrathoracic pressure and therefore the preload and afterload of the right and left ventricles [17]. Especially the right ventricle, compared to the left ventricle, is highly sensitive to the increase in afterload [18]. Therefore, the amount of the applied PEEP level, the influence of alveolar pressure (Palv) transmission on pleural pressure $(\mathrm{Ppl})$, and the lung's compliance can have a significant impact, especially on the right heart and risks of right heart failure $[18,19]$. This is one of the reasons that right ventricular (RV) dysfunction and failure should be actively monitored in patients with severe COVID-19 lung involvement. Even in nonprogressed COVID-19 stages, the RV function has shown to deteriorate depending on the pulmonary arterial pressure, direct or indirect lung injury, hypoxic vasoconstriction of the pulmonary microvasculature, micro- or macrovascular thrombotic processes, myocardial injury, and mechanical effects of the mechanical ventilator [20]. The presence of venous congestion and obstructed lymphatic drainage due to RV dysfunction can lead to decreased secondary organ perfusion pressure due to venous pressure-induced tamponade, especially in kidneys potentially provoking acute kidney injury (AKI) [21, 22].

\section{Renal Injury and Cardiorenal Interactions in COVID-19}

Initially, a low incidence of AKI has been reported in patients with confirmed COVID-19 [23]. Guan and colleagues [24] reported an AKI incidence of between 0.1 and $6 \%$ in around 1,100 patients with COVID-19 in China. A large portion of these patients had normal kidney functions, and the reported data seem similar to what would be expected from patients hospitalized with acute illnesses. However, recent reports show a higher incidence of AKI depending on the ethnicity, country, and the severity of the disease in COVID-19 [25]. Critically ill COVID-19 patients had increased risk for AKI 7-56\%, 
Lung injury

* Direct lung injury

* Hypoxic vasoconstriction

* Lung edema

* Micro- and macrovascular thrombosis

* Side effects of mechanical ventilation

* Pulmonary hypertension

* Ventilation/perfusion mismatch

* Inflammation and endothelial dysfunction

Heart injury

* Direct cardiac injury, myocarditis

* Left heart dysfunction

* Right heart dysfunction

* Cardiac arrhythmias

* Myocardial infarction

* Drug-induced cardiotoxicity

* Inflammation and endothelial dysfunction

* Septic cardiomyopathy

Kidney injury

* Direct kidney injury

* Acute renal dysfunction due venous congestion

* Increased vascular permeability

* Inflammation and endothelial dysfunction

* Renovascular microthrombus

* Vasoactive therapy

* Acute tubular necrosis secondary to septic or cardiogenic shock

* Nephrotoxins

* Drugs-induced nephropathy

* Contrast induced nephropathy

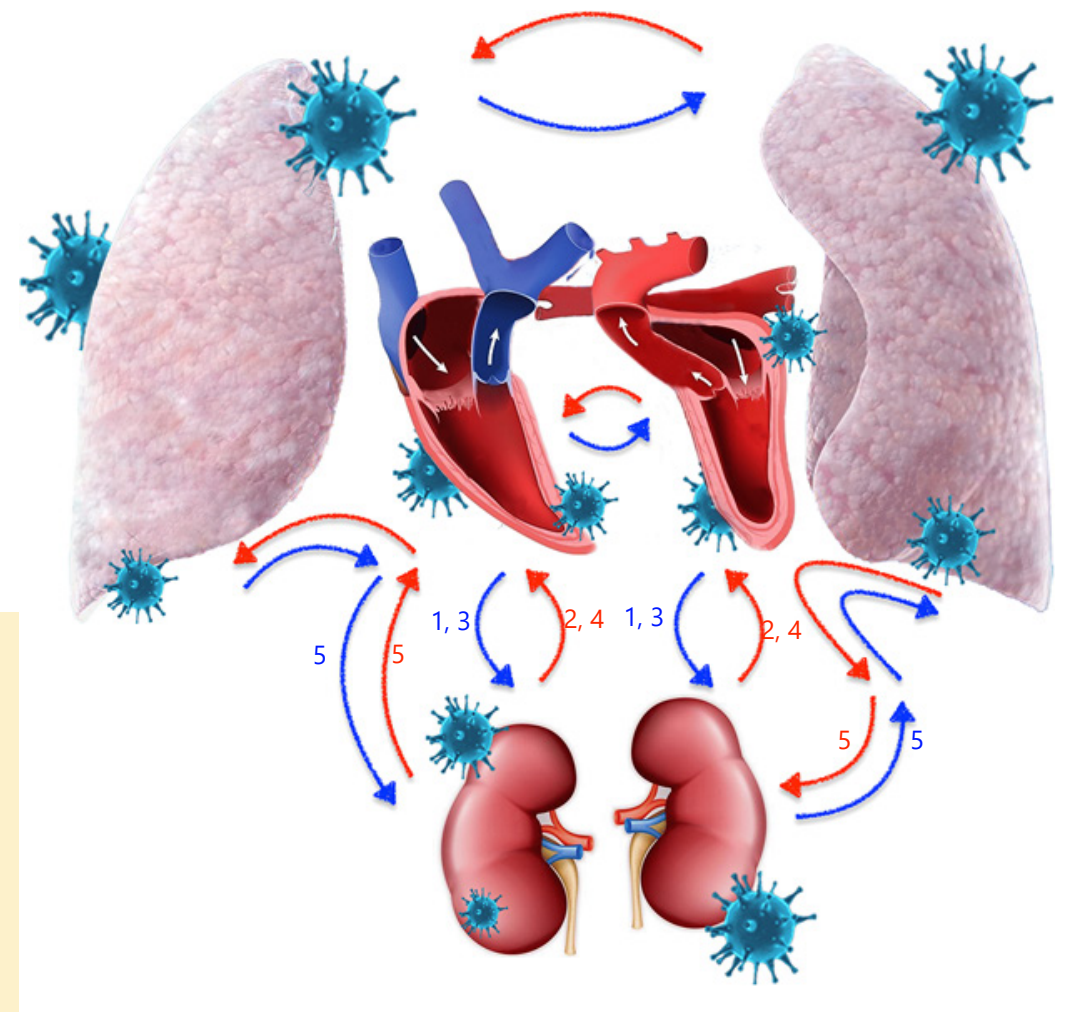

Fig. 1. Cardiac, pulmonary, and renal injury and interactions in COVID-19 infection. CRS, cardiorenal syndrome; 1 , type 1 CRS; 2 , type CRS; 3 , type 3 CRS; 4 , type 4 CRS; 5 , type 5 CRS.

where the development of AKI was highly related to increased mortality, even up to $80 \%$ among ICU population $[9,26]$. Given the impact of AKI in patients with COVID-19, experts on the kidney have designed a consensus report that can help in disease management [27].

Independently from its origin, ARDS patients have increased risk for the development of AKI [28]. In fact, AKI is the most prevalent extrapulmonary organ failure in ARDS [29]. The responsible mechanism includes an inflammatory and hemodynamic crosstalk between the lung, heart, and kidneys [29, 30]. The kidney and heart display a bidirectional interaction whereby an acute or chronic dysfunction in one affects the other. This concept is known as cardiorenal syndrome (CRS) and has been well defined in several preclinical and clinical studies [31]. However, the pathophysiologic basis of COVID19-related organ dysfunction is complicated and characterized by unique changes that are specific for COVID-19.
The responsible mechanisms that might be responsible for the development of COVID-19-related CRS are summarized in Figure 1.

AKI caused by cardiac dysfunction due to ARDS itself or direct cardiac injury can be classified as type 1 CRS. On the other hand, the occurrence of heart and kidney injury due to the systemic effects of inflammation constitutes type 5 CRS's pathophysiology. From the point of the microvascular level, the cytokines released secondary to systemic inflammation, increased vascular permeability due to endothelial activation, renovascular microthrombus formation, intravascular fluid depletion or on the contrary venous congestion secondary to volume overload, and excess vasoactive or fluid therapy all could contribute to the deterioration in kidney function $[32,33]$. Therefore, the kidneys that already have physiologically low tissue oxygen levels could become even more vulnerable to 
hypoxia in the setting of acute respiratory failure and ARDS [34]. Moreover, the kidney injury might occur as a complication of medications used for nonrenal indications.

The current available data suggest that potential causes of COVID-19-associated kidney injury can be explained by the action of 2 main mechanisms: direct effects of COVID-19, indirect effects of systemic inflammation, and/ or organ-organ crosstalk. Recently, Pan and colleagues [35] showed that proximal tubules and podocytes coexpress ACE-2 and TMPRSS. Also, SARS-CoV-2 has been detected in urine swabs of COVID-19 patients [23]. Another study performed on autopsy specimens revealed that the kidneys are affected by the SARS-CoV-2 virus independently from the presence of CKD. In that study, the SARS-CoV-2 preferentially targeted the glomerular cells even though the viral load was displayed in all kidney compartments [36]. Thus, it seems that COVID-19 can invade renal cells and lead to clinical manifestations ranging from proteinuria to AKI $[35,37]$. Moreover, they revealed that the ACE-2 receptor is expressed more in Westerners than in Asian population [35]. The clinical impact of this finding remains to be determined.

The requirement for renal replacement therapy was found to be around 20\% among patients having severe COVID-19 [38, 39]. Interestingly, preexisting CKD was not found to be a risk factor for COVID-19 infection [38]. Similarly, Wang et al. [26] showed that CKD is not a risk factor for COVID-19 infection, irrespective of the patients' stay in the ICU or ward. This finding is puzzling since hypertension is a common complication in patients with CKD, despite it being one of the leading risk factors for COVID-19. The limited number of CKD patients enrolled in these 2 studies could explain the reason behind this controversy. In support of these findings, when enrolling more patients, Graselli and colleagues [40] showed that the patients with CKD have higher risk for mortality for COVID-19.

\section{Proactive Hemodynamic Monitoring in COVID-19}

Hemodynamic compromise is frequently detected in critically ill COVID-19 patients. Proactive hemodynamic monitoring starting in the emergency department and non-ICU wards could enable early recognition of hemodynamically deteriorating COVID-19 patients and allow earlier intervention. Noninvasive monitoring tools including ultrasound and echocardiography have been widely used to assess cardiac function and predict fluid responsiveness in these patients [41]. Moreover, hemodynamic parameters such as blood pressure, cardiac output, pulse pressure variation, pleth variability index, and systemic vascular resistance can noninvasively be measured. Although noninvasive monitoring techniques have several limitations, they could be used, especially in limited access to resources and qualified healthcare workers.

During their stay in the ICU, almost $>30 \%$ of patients require vasopressor therapy $[26,42,43]$. Due to its infective origin, COVID-19-related shock could be classified as a septic shock where the underlying reason for the hypotension is of a distributive shock [44]. Second, COVID-19 patients could be prone to relative hypovolemia due to restrictive fluid administration, excessive insensible fluid loss, or diuretic therapy aimed at keeping the patients dry [23]. Third, secondary to increased pulmonary arterial pressures (secondary to ARDS), need of mechanical ventilation with high pressures or frequently encountered pulmonary embolism may induce right heart failure and compromise secondary organ perfusion including the liver, intestines, and the kidneys $[18,20]$. Last but not least, direct cardiac injury due to myocarditis or myocardial depression could decrease heart pump function and exacerbate tissue hypoperfusion $[10,45]$.

In clinical practice, recognition of the underlying pathophysiologic mechanisms causing the deterioration in hemodynamics could be achieved by measuring dynamic and static hemodynamic parameters. Dynamic hemodynamic indices have been shown to be superior to static hemodynamic indices [46]. Therefore, continuous hemodynamic monitoring and regular echocardiographic imaging is pivotal. Unfortunately, only continuous monitoring of arterial pressure is not enough to assess heart-lung interaction although it seems to be common practice in COVID-19 patients today. Continuous hemodynamic monitoring by inserting a pulmonary arterial catheter or less-invasive thermodilution techniques such as pulse contour cardiac output monitoring including the measurement of the extravascular lung water and pulmonary vascular permeability index might be helpful due to providing comprehensive hemodynamic data.

The techniques mentioned above are used to estimate "classic" macrohemodynamic parameters, which might not always show parallel changes with microcirculatory indices. This concept is known as "loss of hemodynamic coherence" and well described, especially in critically ill patients [47]. Since the main target for optimizing the macrocirculation is to provide sufficient oxygen and blood flow to the tissues, there will be need of novel tech- 
niques to assess the microcirculation [48, 49]. Hand-held vital microscopes might be good candidates for the bedside evaluation of microcirculation in critically ill COVID-19 patients. Hand-held vital microscopes enable direct monitorization of the microvessels and might allow a point of care assessment of the applied therapy using newly introduced automatic analysis called MicroTools [48-50]. Besides, serum lactate level, capillary refill time, and mottling score could also indirectly monitor the microcirculation [51].

\section{Proposal for a Proactive Hemodynamic Management of COVID-19}

Prevention of hospitalization and subsequently severe clinical complications would be of the uttermost importance. Unfortunately, no single effective treatment or medication is yet available except prevention with novel vaccines. Prehospital initiation of the sequenced multidrug therapy including adjuvant nutraceuticals, the combination of anti-infective therapy, inhaled/oral corticosteroids, antiplatelets/anticoagulants, and supplemental oxygen along with active telemonitoring have been proposed to mitigate the intensity and duration of COVID19 -associated symptoms and complications. This could decrease the majority of hospitalizations and, by extension, development of cardio-pulmonary-renal complications and deaths $[52,53]$.

Once progressively ill, advanced hemodynamic management of COVID-19 patients should be applied in critical care settings with access to conventional and complex treatment. Surviving Sepsis Campaign guideline for COVID-19 published by the European Society of Intensive Care Medicine experts suggests a conservative fluid strategy in critically ill COVID-19 patients [44]. Albeit fluid therapy in critical illness aims at achieving adequate blood flow required for tissue oxygenation, both excess and inadequate fluid can cause tissue hypoxia. Therefore, fluid therapy of critical illness might be considered as a 2-edged sword, which makes monitoring the amount of fluid given and monitoring the fluid responsiveness critical at the bedside. Furthermore, due to the endothelial damage in COVID-19, excessive fluid therapy could be harmful leading to tissue edema and pulmonary capillary leakage [54]. Moreover, an increase in right heart pressure might facilitate the deterioration in ventilation/perfusion mismatch and worsen the arterial and tissue hypoxia [20,21, 31 ]. On the other hand, inadequate fluid therapy leads to hypovolemia and tissue hypoxia [9]. Targeting central ve- nous pressure $<10 \mathrm{~mm} \mathrm{Hg}$ could avoid hypervolemia [21].

If the patient is hypotensive despite adequate fluid therapy, a vasopressor should be added to therapy instead of giving more fluids [44]. Norepinephrine is preferred as the first-line vasoactive agent, and titrating the dose until the mean arterial pressure reaches $60-65 \mathrm{~mm} \mathrm{Hg}$ seems better than targeting a higher mean arterial pressure level. Vasopressin or epinephrine could be the second-line therapy if norepinephrine is insufficient. Having low $\mathrm{ScvO}_{2}$ despite adequate hemoglobin level should remind adding dobutamine to the therapy to compensate the failing heart [44]. For ongoing cardiopulmonary failure and shock, extracorporeal membrane oxygenation should be considered given the clinical successes with extracorporeal membrane oxygenation in the treatment of critically ill H1N1 influenza epidemics [55].

\section{Conclusion}

In this brief report, we summarize the pathogenesis and current evidence of renal and cardiorenal complications in patients with COVID-19. Acute kidney injury and cardiac injury are common in critically ill COVID-19 patients and are associated with high mortality. Understanding the interaction between 2 organs in COVID-19 and recognizing the factors affecting organ functions can provide more accurate treatment and monitoring approaches. Proactive micro- and macrohemodynamic monitoring and timely intervention could prevent progressive multiorgan failure, including the $\mathrm{AKI}$ and its dire sequelae. Future studies focusing on the disease pathophysiology of secondary organ injury are needed to learn more about the renal and cardiorenal interactions in COVID-19.

\section{Statement of Ethics}

The study is exempt from ethics committee approval due to the nature of the study. This is a review article and does not include human or animal subjects' material or data.

\section{Conflict of Interest Statement}

The authors have no conflicts of interest to declare. 


\section{Funding Sources}

The authors did not receive any funding.

\section{Author Contributions}

G.G. and K.C.: conception, design, and drafting of the work. G.G., C.I., A.T., and K.C.: revising critically for important intellectual content. G.G., C.I., A.T., and K.C.: final approval of the version to be published.

\section{References}

1 Woo PC, Lau SK, Lam CS, Lau CC, Tsang AK, Lau JH, et al. Discovery of seven novel mammalian and avian coronaviruses in the genus deltacoronavirus supports bat coronaviruses as the gene source of alphacoronavirus and betacoronavirus and avian coronaviruses as the gene source of gammacoronavirus and deltacoronavirus. J Virol. 2012 Apr;86(7): 3995-4008.

2 Graham RL, Donaldson EF, Baric RS. A decade after SARS: strategies for controlling emerging coronaviruses. Nat Rev Microbiol. 2013 Dec;11(12):836-48.

3 Zumla A, Hui DS, Perlman S. Middle East respiratory syndrome in the shadow of Ebola. Lancet Respir Med. 2015;3:100.

4 Situation Report - 55. [cited 2020 Mar 16]. Available from: https://www.who.int/docs/ default-source/coronaviruse/situationreports/20200315-sitrep-55-covid-19. pdf?sfvrsn=33daa5cb_6.

5 Ackermann M, Verleden SE, Kuehnel M, Haverich A, Welte T, Laenger F, et al. Pulmonary vascular endothelialitis, thrombosis, and angiogenesis in Covid-19. N Engl J Med. 2020 Jul;383(2):120-8.

6 Pons S, Fodil S, Azoulay E, Zafrani L. The vascular endothelium: the cornerstone of organ dysfunction in severe SARS-CoV-2 infection. Crit Care. 2020 Dec;24(1):353.

7 Guo T, Fan Y, Chen M, Wu X, Zhang L, He T, et al. Cardiovascular implications of fatal outcomes of patients with coronavirus disease 2019 (COVID-19). JAMA Cardiol. 2020 Jul; 5(7):811.

8 Li B, Yang J, Zhao F, Zhi L, Wang X, Liu L, et al. Prevalence and impact of cardiovascular metabolic diseases on COVID-19 in China. Clin Res Cardiol. 2020 May;109(5):531-8.

9 Gabarre P, Dumas G, Dupont T, Darmon M, Azoulay E, Zafrani L. Acute kidney injury in critically ill patients with COVID-19. Intensive Care Med. 2020 Jul;46(7):1339-48.

10 Li X, Guan B, Su T, Liu W, Chen M, Bin Waleed K, et al. Impact of cardiovascular disease and cardiac injury on in-hospital mortality in patients with COVID-19: a systematic review and meta-analysis. Heart. 2020 Aug; 106(15):1142-7.

11 Chen N, Zhou M, Dong X, Qu J, Gong F, Han $\mathrm{Y}$, et al. Epidemiological and clinical characteristics of 99 cases of 2019 novel coronavirus pneumonia in Wuhan, China: a descriptive study. Lancet. 2020 Feb;395(10223):507-13.
12 Li Q, Guan X, Wu P, Wang X, Zhou L, Tong $\mathrm{Y}$, et al. Early transmission dynamics in $\mathrm{Wu}$ han, China, of novel coronavirus-infected pneumonia. N Engl J Med. 2020 Mar;382(13): 1199-207.

13 Hoffmann M, Kleine-Weber H, Schroeder S, Krüger N, Herrler T, Erichsen S, et al. SARSCoV-2 cell entry depends on ACE2 and TMPRSS2 and is blocked by a clinically proven protease inhibitor. Cell. 2020 Apr;181(2): 271-e8.

14 Hippisley-Cox J, Young D, Coupland C, Channon KM, Tan PS, Harrison DA, et al. Risk of severe COVID-19 disease with ACE inhibitors and angiotensin receptor blockers: cohort study including 8.3 million people. Heart. 2020 Jul;106(19):1503-11.

15 Zhang H, Penninger JM, Li Y, Zhong N, Slutsky AS. Angiotensin-converting enzyme 2 (ACE2) as a SARS-CoV-2 receptor: molecular mechanisms and potential therapeutic target. Intensive Care Med. 2020 Apr;46(4):58690.

16 Gattinoni L, Chiumello D, Caironi P, Busana M, Romitti F, Brazzi L, et al. COVID-19 pneumonia: different respiratory treatments for different phenotypes? Intensive Care Med. 2020 Jun;46(6):1099-102.

17 Alviar CL, Miller PE, McAreavey D, Katz JN, Lee B, Moriyama B, et al. Positive pressure ventilation in the cardiac intensive care unit. J Am Coll Cardiol. 2018 Sep;72(13):1532-53.

18 Mahmood SS, Pinsky MR. Heart-lung interactions during mechanical ventilation: the basics. Ann Transl Med. 2018 Sep;6(18):349.

19 Marini JJ, Gattinoni L. Management of COVID-19 respiratory distress. JAMA. 2020 Jun; 323(22):2329.

20 Pagnesi M, Baldetti L, Beneduce A, Calvo F, Gramegna M, Pazzanese V, et al. Pulmonary hypertension and right ventricular involvement in hospitalised patients with $\mathrm{CO}$ VID-19. Heart. 2020;106(17):1324-31.

21 Guven G, Brankovic M, Constantinescu AA, Brugts JJ, Hesselink DA, Akin S, et al. Preoperative right heart hemodynamics predict postoperative acute kidney injury after heart transplantation. Intensive Care Med. 2018 May;44(5):588-97.

22 Telinius N, Hjortdal VE. Role of the lymphatic vasculature in cardiovascular medicine. Heart. 2019 Dec;105(23):1777-84.
23 Wang L, Li X, Chen H, Yan S, Li D, Li Y, et al. Coronavirus disease 19 infection does not result in acute kidney injury: an analysis of 116 hospitalized patients from Wuhan, China. Am J Nephrol. 2020;51(5):343-8.

24 Guan W, Ni Z, Hu Y, Liang W, Ou C, He J, et al. Clinical characteristics of coronavirus disease 2019 in China. N Engl J Med. 2020 Apr; 382(18):1708-20.

25 Fanelli V, Fiorentino M, Cantaluppi V, Gesualdo L, Stallone G, Ronco C, et al. Acute kidney injury in SARS-CoV-2 infected patients. Crit Care. 2020 Dec;24(1):155.

26 Wang D, Hu B, Hu C, Zhu F, Liu X, Zhang J, et al. Clinical characteristics of 138 hospitalized patients with 2019 novel coronavirus-infected pneumonia in Wuhan, China. JAMA. 2020 Mar;323(11):1061.

27 Nadim MK, Forni LG, Mehta RL, Connor MJ, Liu KD, Ostermann M, et al. COVID-19-associated acute kidney injury: consensus report of the 25th Acute Disease Quality Initiative (ADQI) Workgroup. Nat Rev Nephrol. 2020 Oct;16(12):747-64.

28 Ali H, Daoud A, Mohamed MM, Salim SA, Yessayan L, Baharani J, et al. Survival rate in acute kidney injury superimposed COVID-19 patients: a systematic review and meta-analysis. Ren Fail. 2020 Jan;42(1):393-7.

29 Darmon M, Clec'h C, Adrie C, Argaud L, Allaouchiche B, Azoulay E, et al. Acute respiratory distress syndrome and risk of AKI among critically Ill patients. Clin J Am Soc Nephrol. 2014 Aug;9(8):1347-53.

30 Pettenuzzo T, Pichette M, Doufle G, Fan E. Effect of ultraprotective mechanical ventilation on right ventricular function during extracorporeal membrane oxygenation in adults with acute respiratory distress syndrome. J Cardiothorac Vasc Anesth. 2021 Jun;35(6):1906-8.

31 Ronco C, Haapio M, House AA, Anavekar N, Bellomo R. Cardiorenal syndrome. J Am Coll Cardiol. 2008 Nov;52(19):1527.

32 Su H, Yang M, Wan C, Yi L-X, Tang F, Zhu H-Y, et al. Renal histopathological analysis of 26 postmortem findings of patients with COVID-19 in China. Kidney Int. 2020 Jul;98(1):219-27.

33 Colantuoni A, Martini R, Caprari P, Ballestri M, Capecchi PL, Gnasso A, et al. COVID-19 sepsis and microcirculation dysfunction. Front Physiol. 2020 Jun;11:747.

34 van Bommel J, Siegemund M, ChP H, Ince C. Heart, kidney, and intestine have different tolerances for anemia. Transl Res. $2008 \mathrm{Feb}$; 151(2):110-7. 
35 Pan X, Xu D, Zhang H, Zhou W, Wang L, Cui $\mathrm{X}$. Identification of a potential mechanism of acute kidney injury during the COVID-19 outbreak: a study based on single-cell transcriptome analysis. Intensive Care Med. 2020 Jun;46(6):1114-6.

36 Puelles VG, Lütgehetmann $M$, Lindenmeyer MT, Sperhake JP, Wong MN, Allweiss L, et al. Multiorgan and renal tropism of SARSCoV-2. N Engl J Med. 2020 Aug;383(6):5902.

37 Cheng Y, Luo R, Wang K, Zhang M, Wang Z, Dong $L$, et al. Kidney disease is associated with in-hospital death of patients with COVID-19. Kidney Int. 2020 May;97(5):829-38.

38 Yang X, Yu Y, Xu J, Shu H, Xia J, Liu H, et al. Clinical course and outcomes of critically ill patients with SARS-CoV-2 pneumonia in Wuhan, China: a single-centered, retrospective, observational study. Lancet Respir Med. 2020 May;8(5):475-81.

39 Gupta S, Coca SG, Chan L, Melamed ML, Brenner SK, Hayek SS, et al. AKI treated with renal replacement therapy in critically Ill patients with COVID-19. J Am Soc Nephrol. 2021 Jan;32(1):161-76.

40 Grasselli G, Greco M, Zanella A, Albano G, Antonelli M, Bellani G, et al. Risk factors associated with mortality among patients with COVID-19 in intensive care units in Lombardy, Italy. JAMA Intern Med. 2020 Jul;180(10): 1345-55.

41 Michard F, Malbrain ML, Martin GS, Fumeaux T, Lobo S, Gonzalez F, et al. Haemodynamic monitoring and management in COVID-19 intensive care patients: an International survey. Anaesth Crit Care Pain Med. 2020 Oct;39(5):563-9.
42 Xie J, Wu W, Li S, Hu Y, Hu M, Li J, et al. Clinical characteristics and outcomes of critically ill patients with novel coronavirus infectious disease (COVID-19) in China: a retrospective multicenter study. Intensive Care Med. 2020 Oct;46(10):1863-72.

43 Michard F, Vieillard-Baron A. Critically ill patients with COVID-19: are they hemodynamically unstable and do we know why? Intensive Care Med. 2020 Sep;47(2):254-5.

44 Alhazzani W, Møller MH, Arabi YM, Loeb M, Gong MN, Oczkowski S, et al. Surviving sepsis campaign: guidelines on the management of critically Ill adults with coronavirus disease 2019 (COVID-19). Crit Care Med. 2020;48: e440.

45 Kang Y, Chen T, Mui D, Ferrari V, Jagasia D, Scherrer-Crosbie $\mathrm{M}$, et al. Cardiovascular manifestations and treatment considerations in COVID-19. Heart. 2020 Aug; 106(15): 1132-41.

46 Bednarczyk JM, Fridfinnson JA, Kumar A, Blanchard L, Rabbani R, Bell D, et al. Incorporating dynamic assessment of fluid responsiveness into goal-directed therapy: a systematic review and meta-analysis. Crit Care Med. 2017 Sep;45(9):1538-45.

47 Ince C. Hemodynamic coherence and the rationale for monitoring the microcirculation. Crit Care. 2015 Dec;19(Suppl 3):S8.

48 On behalf of the Cardiovascular Dynamics Section of the ESICM; Ince C, Boerma EC, Cecconi M, De Backer D, Shapiro NI, et al. Second consensus on the assessment of sublingual microcirculation in critically ill patients: results from a task force of the European Society of Intensive Care Medicine. Intensive Care Med. 2018 Mar;44(3):281-99.
49 Ince C. The rationale for microcirculatory guided fluid therapy. Curr Opin Crit Care. 2014 Jun;20(3):301-8.

50 Hilty MP, Akin S, Boerma C, Donati A, Erdem Ö, Giaccaglia P, et al. Automated algorithm analysis of sublingual icrocirculation in an international multicentral database identifies alterations associated with disease and mechanism of resuscitation. Crit Care Med. 2020;48(10):e864.

51 Messina A, Collino F, Cecconi M. Fluid administration for acute circulatory dysfunction using basic monitoring. Ann Transl Med. 2020 Jun;8(12):788-.

52 McCullough PA, Eidt J, Rangaswami J, Lerma E, James T, Kevin W, et al. Urgent need for individual mobile phone and institutional reporting of at home, hospitalized, and intensive care unit cases of SARS-CoV-2 (COVID-19) infection. Rev Cardiovasc Med. 2020;21(1):1-7.

53 McCullough PA, Alexander PE, Armstrong R, Arvinte C, Bain AF, Bartlett RP, et al. Multifaceted highly targeted sequential multidrug treatment of early ambulatory high-risk SARS-CoV-2 infection (COVID-19). Rey Cardiovasc Med. 2020 Dec 30;21(4):517-30.

54 Teuwen L-A, Geldhof V, Pasut A, Carmeliet P. COVID-19: the vasculature unleashed. Nat Rev Immunol. 2020 Jul;20(7):389-91.

55 Australia and New Zealand Extracorporeal Membrane Oxygenation (ANZ ECMO) Influenza Investigators; Davies A, Jones D, Bailey M, Beca J, Bellomo R, Blackwell N, et al. Extracorporeal membrane oxygenation for 2009 influenza $\mathrm{A}(\mathrm{H} 1 \mathrm{~N} 1)$ acute respiratory distress syndrome. JAMA. 2009;302(17): 1888-95. 